\title{
Prediction of free air space in initial composting mixtures by a statistical design approach
}

\author{
Micaela A.R. Soares ${ }^{\mathrm{a}, \mathrm{b}, *}$, Margarida J. Quina ${ }^{\mathrm{b}}$, Rosa Quinta-Ferreira ${ }^{\mathrm{b}}$ \\ ${ }^{a}$ Cernas - Natural Resources, Environment and Society Research Centre, College of Agriculture, Polytechnic Institute of Coimbra, Bencanta, P-3040-316 \\ Coimbra, Portugal \\ ${ }^{\mathrm{b}}$ CIEPQPF - Research Centre on Chemical Processes Engineering and Forest Products, Department of Chemical Engineering, University of Coimbra, \\ Pólo II - Rua Sílvio Lima, P-3030-790 Coimbra, Portugal
}

\section{A R T I C L E I N F O}

\section{Article history:}

Received 28 December 2012

Received in revised form

10 April 2013

Accepted 16 April 2013

Available online 27 May 2013

\section{Keywords:}

Industrial potato peel

Free air space

Mixture design

Composting

\begin{abstract}
A B S T R A C T
Free air space (FAS) is a physical parameter that can play an important role in composting processes to maintain favourable aerobic conditions. Aiming to predict the FAS of initial composting mixtures, specific materials proportions ranged from 0 to 1 were tested for a case study comprising industrial potato peel, which is characterized by low air void volume, thus requiring additional components for its composting.

The characterization and prediction of FAS for initial mixtures involving potato peel, grass clippings and rice husks (set $\mathrm{A}$ ) or sawdust (set $\mathrm{B}$ ) was accomplished by means of an augmented simplex-centroid mixture design approach. The experimental data were fitted to second order Scheffé polynomials. Synergistic or antagonistic effects of mixture proportions in the FAS response were identified from the surface and response trace plots in the FAS response. Moreover, a good agreement was achieved between the model predictions and supplementary experimental data. Moreover, theoretical and empirical approaches for estimating FAS available in literature were compared with the predictions generated by the mixture design approach.

This study demonstrated that the mixture design methodology can be a valuable tool to predict the initial FAS of composting mixtures, specifically in making adjustments to improve composting processes containing primarily potato peel.
\end{abstract}

(c) 2013 Elsevier Ltd. All rights reserved.

\section{Introduction}

Potato peel (PP) waste is a by-product from the processed potato products industries such as French fries, chips and puree. Although PP is a zero value waste for those plants, disposal, sanitation, and environmental problems must be overcome (Arapoglou et al., 2010). During the processing of potatoes at industrial level, depending on the technology used (steam, abrasion or lye peeling) losses caused by potato peeling can reach $15-40 \%$ of the total raw materials (Schieber et al., 2001).

Though the food industry manages PP waste as a non-valuable by-product, its composition may be suitable for several applications such as dietary fibre for baking products and animal feeding (Djomo et al., 2008), biohydrogen and ethanol production (Arapoglou et al., 2010; Djomo et al., 2008; Mars et al., 2010), source of natural antioxidants (Al-Weshahy et al., 2013; Schieber et al.,

\footnotetext{
* Corresponding author. Cernas - Natural Resources, Environment and Society Research Centre, College of Agriculture, Polytechnic Institute of Coimbra, Bencanta P-3040-316 Coimbra, Portugal. Tel.: +351 964492191.

E-mail address: msoares@esac.pt (M.A.R. Soares).
}

2001; Wijngaard et al., 2012) and bio-methane production (Parawira et al., 2004; Kaparaju and Rintala, 2005; Kryvoruchko et al., 2009). Our study addressed the PP valorisation through composting. This process may be defined as the biological decomposition and stabilization of organic subtracts, under aerobic conditions that allow development of thermophilic temperatures, as result of biologically generated heat, to obtain a final product that is stable, free of pathogens and plant seeds, that can be beneficially applied to land (Haug, 1993). It should be noted that PP valorisation by composting can be quite interesting for the food industry, given that a volume reduction of by-products up to $40 \%$ can be achieved (Schaub and Leonard, 1996). Nevertheless, to the best of our knowledge, PP composting has been scarcely addressed in literature. PP waste is usually characterized by high interparticle water content which might hinder composting evolution, due to higher oxygen diffusion resistance in pores between particles. Therefore, its valorization may require previous mixture with other materials, aiming to reach an adequate formulation for composting.

Mixture formulations for composting are often based on physical and chemical properties of the wastes (Barrena et al., 2011) in 
order to adjust moisture content and C: $\mathrm{N}$ ratio to optimal values that favor growth and activity of microbial populations. Indeed, it is well known that one of the most important factors for thermophilic composting is the carbon to nitrogen ratio $(\mathrm{C} / \mathrm{N})$ with optimum values around 25-30:1 (Abdullah and Chin, 2010; Hamoda et al., 1998; Huang et al., 2006) and moisture content in the range of 50-65\% (Abdullah and Chin, 2010; Liang et al., 2003).

However, more recently the free air space (FAS) of a mixture has also been indicated as a physical property that may play an important role during composting (Agnew et al., 2003; Barrena et al., 2011; Eftoda and McCartney, 2004; Richard et al., 2004; Ruggieri et al., 2009). This parameter is defined as the ratio of gas filled pore volume to total compost mixture volume and it determines the air quantity and movement inside the mixture, as well as the intrinsic air content, carbon dioxide, moisture and heat removal from the system (Richard et al., 2004; Ruggieri et al., 2009). FAS depends on the structural characteristics of the materials used such as bulk density, particle density and water content. A minimum value of $30 \%$ is usually required to ensure aerobic condition in the composting mixture (Haug, 1993), and optimum values for FAS may be in the range of $60 \%$. In literature there are references to FAS as high as 85-90\% without significant negative impact (Ahn et al., 2008; Ruggieri et al., 2009). To quantify FAS for a given composting mixture, some theoretical empirical correlations have been developed (Agnew et al., 2003; Haug, 1993, Oppenheimer et al., 1997; Richard et al., 2004). Moreover, experimental procedures by using air pycnometry have been studied and compared (Ruggieri et al., 2009). But so far, the study of an approach able to predict FAS for a given mixture based on its individual components proportions has been seldom addressed (Soares et al., 2012).

Mixture design is a statistical technique associated to the concept of planning and execution of informative experiments concerning a mixture of different components, and it has been widely used to establish formulations in chemical, pharmaceutical and food industries (Eriksson, 1998). The method consists in varying the proportions of two or more ingredients of the mixture and studying the influence of the independent variables (proportions of different components) into the measured response, which is dependent on the ingredient composition (Akalin et al., 2010).

In this scope, our work aims to use the mixture design approach to understand and predict the influence of each component, on the FAS of an initial mixture containing primarily potato peel waste (PP) for further composting. Rice husk (RH) or sawdust (SD) were selected as bulking agents, and grass clippings (GC) as nitrogen source.

\section{Materials and methods}

\subsection{Composting materials}

The materials used were collected from different sources: potato peel (PP) is from a national industry of potato chips, rice husk ( $\mathrm{RH})$ was provided by a rice husking factory, sawdust (SD) is from a local pine sawmill, and grass clippings (GC) were obtained from a national football stadium. Grass clippings were sieved through a $5 \mathrm{~cm}$ mesh to obtain a homogeneous material in size and shape. The other materials did not require any specific treatment. The characterization of the each material was carried out using a composite sample of $25 \mathrm{~L}$ obtained from five individual samples of $5 \mathrm{~L}$ taken from the initial laboratory samples of about $120 \mathrm{~L}$. Then, each composite sample of $25 \mathrm{~L}$ was homogenized and divided into four parts, with one being eliminated. This procedure was repeated until samples of about 1-2 L were obtained for further analysis.

\subsection{Mixture design establishment and validation}

The mixtures tested in this study were grouped in two sets (Set A and Set B) according to the type of bulking agent used. Each set comprised three mixture factors or ingredients (set $A$ : $\mathrm{PP}+\mathrm{GC}+\mathrm{RH}$ ); (set $\mathrm{B}: \mathrm{PP}+\mathrm{GC}+\mathrm{SD}$ ) and their mixing proportions were individually allowed to range from 0 to 1 .

Therefore, a regular and triangular experimental design region is expected for each set, with the constraint that the sum of all feedstock's proportions must be 1 . Vertices of the design region correspond to the formulations that are pure blends.

The main objective of this design was to predict the free air space (desired response) for any mixture tested by modelling the mixing surface with mathematical equations. It was assumed that the measured response was only dependent on the relative proportions of the ingredients (considered as independent variables) but not on the amount of the mixture.

The models considered in this study were Scheffé canonical polynomials (Smith, 2005):

Linear:

$$
E(Y)=\sum_{i=1}^{q} \beta_{i} X_{i}
$$

Quadratic:

$$
E(Y)=\sum_{i=1}^{q} \beta_{i} X_{i}+\sum_{i=1}^{q-1} \sum_{j=i+1}^{q} \beta_{i j} X_{i} X_{j}
$$

Special cubic:

$$
\begin{aligned}
E(Y)= & \sum_{i=1}^{q} \beta_{i} X_{i}+\sum_{i=1}^{q-1} \sum_{j=i+1}^{q} \beta_{i j} X_{i} X_{j} \\
& +\sum_{i=1}^{q-2} \sum_{j=i+1}^{q-1} \sum_{k=j+1}^{q} \beta_{i j k} X_{i} X_{j} X_{k}
\end{aligned}
$$

Full cubic:

$$
\begin{aligned}
E(Y)= & \sum_{i=1}^{q} \beta_{i} X_{i}+\sum_{i=1}^{q-1} \sum_{j=i+1}^{q} \beta_{i j} X_{i} X_{j} \\
& +\sum_{i=1}^{q-1} \sum_{j=i+1}^{q} \gamma_{i j} X_{i} X_{j}\left(X_{i}-X_{j}\right) \\
& +\sum_{i=1}^{q-2} \sum_{j=i+1}^{q-1} \sum_{k=j+1}^{q} \beta_{i j k} X_{i} X_{j} X_{k}
\end{aligned}
$$

Special Quartic:

$$
\begin{aligned}
E(Y)= & \sum_{i=1}^{q} \beta_{i} X_{i}+\sum_{i=1}^{q-1} \sum_{j=i+1}^{q} \beta_{i j} X_{i} X_{j} \\
& +\sum_{i=1}^{q-1} \sum_{j=i+1}^{q} \gamma_{i j} X_{i} X_{j}\left(X_{i}-X_{j}\right) \\
& +\sum_{i=1}^{q-2} \sum_{j=i+1}^{q-1} \sum_{k=j+1}^{q} \beta_{i j k} X_{i}^{2} X_{j} X_{k} \\
& +\sum_{i=1}^{q-2} \sum_{j=i+1}^{q-1} \sum_{k=j+1}^{q} \beta_{i j k} X_{i} X_{j}^{2} X_{k} \\
& +\sum_{i=1}^{q-2} \sum_{j=i+1}^{q-1} \sum_{k=j+1}^{q} \beta_{i j k} X_{i} X_{j} X_{k}^{2}
\end{aligned}
$$

where $E(Y)$ is the expected value of the output variable $Y, X$ are the independent variables, $\beta$ and $\gamma$ correspond to the polynomial coefficients, $q$ is the number of components (in this case $q=3$ ).

Since the experimental mixture region is regular and constitutes a simplex shaped region, an augmented simplex-centroid mixture design approach was used to define the number of mixtures necessary to attain the desired response (FAS value). This 


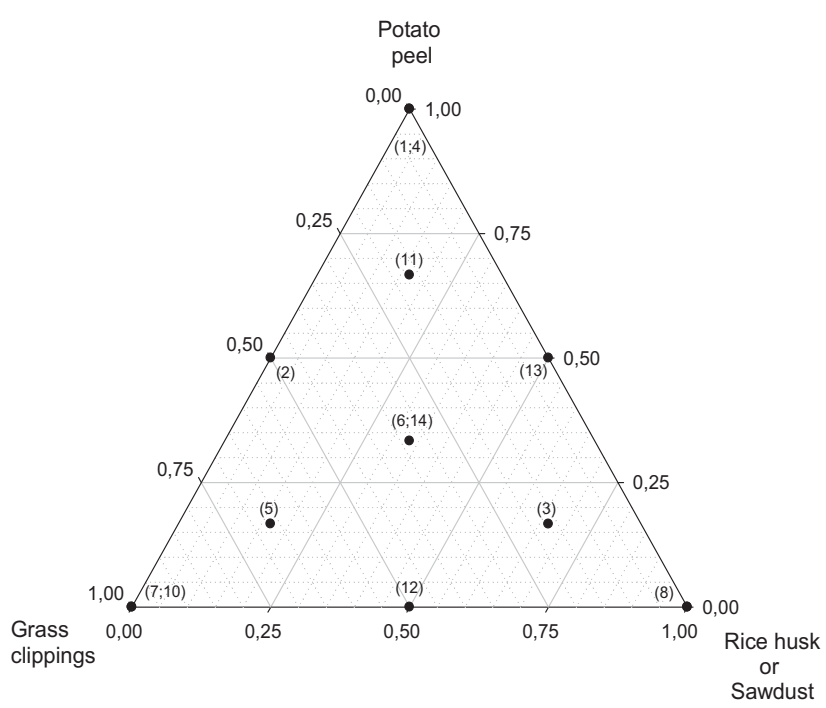

Fig. 1. Mixtures tested according to a simplex-centroid mixture design (values in brackets represent mixture order preparation and analysis).

approach allows to detect the model curvature in the interior of the design region and it includes the points (mixtures) indicated in Fig. 1, namely pure mixtures (vertices of the triangle), binary mixtures (midpoints at each side of the triangle), and mixtures involving three components. In the interior area of the triangle there is a mixture of one third each of all ingredients (called centroid point) and three mixtures located midway between the centroid and each pure material. The pure and centroid mixtures were analysed twice to detect possible lack of fit and pure experimental error. According to this methodology, each set comprised 14 experiments.

Each mix was prepared, for a total load of $2 \mathrm{~kg}$, by weighing the different components and mixing them by hand during $10 \mathrm{~min}$, according to the pre-defined proportions and random sequential order indicated in Fig. 1. Before mixture preparation, every single individual ingredient was manually mixed to promote homogenisation prior to weighing. Design-Expert ${ }^{\circledR}$ version 8.0.4 was used to analyse experimental data and to evaluate of the model that best fits the composition effects in the response variables.

Some extra mixtures were prepared and analysed to validate the response of the model. This assessment was accomplished by comparing the model predictions and experimental FAS values for these specific mixtures.

\subsection{Analytical methods}

The main response variable under analysis is FAS and was calculated according to Eq. (6) (Adhikari et al., 2009):

$\mathrm{FAS}=\left(1-\frac{\mathrm{BD}}{\mathrm{PD}}\right) \times 100 \%$

where BD is the wet bulk density $\left(\mathrm{kg} \mathrm{m}^{-3}\right)$ and PD is the wet particle density of the mixture $\left(\mathrm{kg} \mathrm{m}^{-3}\right)$.

The parameter BD was determined according to a standard procedure described elsewhere (US Department of Agriculture and US Composting Council, 2001), and PD was estimated based on the procedure defined by Adhikari et al. (2009). Water absorption capacity (WAC) of the bulking agents tested was performed as described by Adhikari et al. (2008).

Moisture content of each fresh sample was determined by drying it in an oven at $105^{\circ} \mathrm{C}$ until constant weight. Organic matter was measured as volatile solids (VS) by burning $2.5 \mathrm{~g}$ dry sample in a muffle furnace at $550{ }^{\circ} \mathrm{C}$ for $4 \mathrm{~h}$ (until constant weight). Total organic carbon $\left(\mathrm{C}_{\mathrm{org}}\right)$ was determined in a Carbon-Sulphur Analyzer (Leco Instruments, model SC-144 DR), where carbon was oxidized to carbon dioxide by heating at $550{ }^{\circ} \mathrm{C}$. The total nitrogen content $(\mathrm{N})$ was quantified by elemental analysis (EA 1108 CHNS-O-Fisons). All determinations were performed at least in triplicate.

\section{Results and discussion}

\subsection{Characterization of the composting materials}

Physical and chemical parameters determined for the individual materials are shown in Table 1, where the results were reported by mean \pm standard deviation and the values in brackets indicate the number of samples analysed.

These determinations show that the key component under analysis, PP, is characterized by the highest moisture content and the lowest FAS. Indeed, although PP revealed a favourable $\mathrm{C}_{\mathrm{org}} / \mathrm{N}$ ratio for microbial activity, its valorisation throughout composting may be hindered by the low inter-particle volume of voids available for oxygen diffusion.

With respect to rice husks and sawdust both have been extensively used in composting as structural or drying amendments to reduce bulk density and increase air voids of the mixture (Chang et al., 1999; Chang and Hsu, 2008; Gao et al., 2010; Huang et al., 2006; Jolanun et al., 2008; Nakasaki et al., 1986, 1989). In our

Table 1

Physical and chemical properties of individual mixture components.

\begin{tabular}{|c|c|c|c|c|}
\hline \multirow[t]{2}{*}{ Property } & \multicolumn{4}{|l|}{ Materials tested } \\
\hline & $\mathrm{PP}$ & GC & RH & SD \\
\hline MC (\%) & $85 \pm 2.8(n=8)$ & $75.5 \pm 4.7(n=4)$ & $10.7 \pm 0.5(n=6)$ & $11.6 \pm 0.4(n=9)$ \\
\hline VS (\%) & $95 \pm 1.0(n=7)$ & $84.8 \pm 6.0(n=3)$ & $84.1 \pm 0.0(n=3)$ & $99.7 \pm 0.02(n=6)$ \\
\hline $\mathrm{BD}\left(\mathrm{kg} \mathrm{m}^{-3}\right)$ & $707 \pm 71.1(n=8)$ & $149.2 \pm 27.6(n=3)$ & $122.3 \pm 3.0(n=6)$ & $255.9 \pm 3.0(n=6)$ \\
\hline $\mathrm{PD}\left(\mathrm{kg} \mathrm{m}^{-3}\right)$ & $1016 \pm 21.3(n=5)$ & $1071 \pm 87.0(n=3)$ & $902 \pm 109(n=6)$ & $1525 \pm 243(n=6)$ \\
\hline FAS $(\%)^{\mathrm{a}}$ & $30 \pm 7.0(n=5)$ & $85.7 \pm 1.6(n=3)$ & $86.3 \pm 1.7(n=6)$ & $85 \pm 3.3(n=6)$ \\
\hline $\mathrm{C}_{\text {org }}(\% \mathrm{C}$ on dry basis) & $47 \pm 4.6(n=4)$ & $50 \pm 18.2(n=3)$ & $46.3 \pm 1.14(n=3)$ & $52.1 \pm 0.16(n=3)$ \\
\hline $\mathrm{N}(\% \mathrm{~N}$ on dry basis) & $1.9 \pm 0.4(n=4)$ & $4.5 \pm 3.4(n=3)$ & $0.8 \pm 0.1(n=3)$ & $0.3 \pm 0.09(n=3)$ \\
\hline $\mathrm{C}_{\text {org }} / \mathrm{N}$ & $25.6 \pm 2.5(n=4)$ & $11.4 \pm 2.7(n=3)$ & $57.6 \pm 8.46(n=3)$ & $159 \pm 41.68(n=3)$ \\
\hline WAC $(\%)$ & n.d. & n.d. & 350 & 440 \\
\hline$\%$ Particles retained in a $2 \mathrm{~mm}$ sieve & b & 76 & 47 & 14 \\
\hline
\end{tabular}

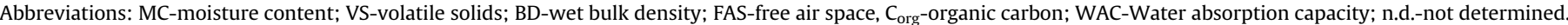

a Calculated by using Eq. (6).

b All particles with dimensions less than $2 \mathrm{~cm}$. 
Table 2

Experimental response values of FAS for set A (with RH) and B (with SD) ( $n=3$ ).

\begin{tabular}{|c|c|c|c|c|c|c|c|c|c|}
\hline \multirow[t]{2}{*}{ Mixture order } & \multicolumn{3}{|c|}{ Independent variables } & \multicolumn{3}{|l|}{ Set $A(R H)$} & \multicolumn{3}{|l|}{ Set B (SD) } \\
\hline & $\mathrm{X}_{1}(\mathrm{PP})$ & $\mathrm{X}_{2}(\mathrm{GC})$ & $\mathrm{X}_{3}(\mathrm{RH}$ or $\mathrm{SD})$ & $\mathrm{BD}\left(\mathrm{kg} \mathrm{m}^{-3}\right) \pm \mathrm{sd}$ & $\mathrm{PD}\left(\mathrm{kg} \mathrm{m}^{-3}\right) \pm \mathrm{sd}$ & FAS (\%) \pm sd & $\mathrm{BD}\left(\mathrm{kg} \mathrm{m}^{-3}\right) \pm \mathrm{sd}$ & $\mathrm{PD}\left(\mathrm{kg} \mathrm{m}^{-3}\right) \pm \mathrm{sd}$ & FAS $(\%) \pm$ sd \\
\hline 1 & 1.000 & 0.000 & 0.000 & $619 \pm 10$ & $938 \pm 40$ & $34.0 \pm 3.0$ & $798 \pm 19$ & $1043 \pm 32$ & $23.5 \pm 3.0$ \\
\hline 2 & 0.167 & 0.167 & 0.667 & $134 \pm 3.2$ & $1348 \pm 3.7$ & $90.1 \pm 0.2$ & $264 \pm 2.1$ & $1213 \pm 55$ & $78.2 \pm 1.0$ \\
\hline 3 & 0.000 & 0.000 & 1.000 & $122 \pm 4.3$ & $833 \pm 50$ & $85.3 \pm 1.0$ & $257 \pm 2.2$ & $1525 \pm 80$ & $83.1 \pm 0.9$ \\
\hline 4 & 0.000 & 0.500 & 0.500 & $118 \pm 1.9$ & $1022 \pm 154$ & $88.4 \pm 1.8$ & $233 \pm 21$ & $1015 \pm 151$ & $77.0 \pm 4.0$ \\
\hline 5 & 1.000 & 0.000 & 0.000 & $625 \pm 8.5$ & $963 \pm 53$ & $35.1 \pm 3.7$ & $788 \pm 14$ & $1053 \pm 21$ & $25.2 \pm 0.9$ \\
\hline 6 & 0.000 & 1.000 & 0.000 & $137 \pm 1.5$ & $1069 \pm 91$ & $87.1 \pm 1.1$ & $179 \pm 8.2$ & $1264 \pm 90$ & $85.8 \pm 1.2$ \\
\hline 7 & 0.000 & 1.000 & 0.000 & $136 \pm 2.0$ & $951 \pm 75$ & $85.7 \pm 1.1$ & $175 \pm 7.7$ & $1257 \pm 72$ & $86.1 \pm 1.0$ \\
\hline 8 & 0.667 & 0.167 & 0.167 & $290 \pm 0.9$ & $879 \pm 18$ & $67.0 \pm 0.7$ & $426 \pm 20$ & $1065 \pm 59$ & $60.0 \pm 2.9$ \\
\hline 9 & 0.333 & 0.333 & 0.333 & $168 \pm 6.7$ & $1198 \pm 18$ & $86.0 \pm 0.6$ & $311 \pm 3.5$ & $1233 \pm 4.7$ & $74.8 \pm 0.3$ \\
\hline 10 & 0.500 & 0.500 & 0.000 & $267 \pm 3.8$ & $1042 \pm 33$ & $74.4 \pm 0.9$ & $343 \pm 23$ & $1197 \pm 23$ & $71.4 \pm 2.0$ \\
\hline 11 & 0.167 & 0.667 & 0.167 & $151 \pm 2.5$ & $1034 \pm 23$ & $85.4 \pm 0.4$ & $238 \pm 9.1$ & $1064 \pm 40$ & $77.6 \pm 1.2$ \\
\hline 12 & 0.000 & 0.000 & 1.000 & $122 \pm 0.9$ & $1013 \pm 46$ & $87.9 \pm 0.6$ & $255 \pm 9.9$ & $1735 \pm 97$ & $85.3 \pm 1.0$ \\
\hline 13 & 0.500 & 0.000 & 0.500 & $178 \pm 0.2$ & $1179 \pm 41$ & $84.9 \pm 0.5$ & $340 \pm 3.6$ & $1219 \pm 64$ & $72.1 \pm 1.5$ \\
\hline 14 & 0.333 & 0.333 & 0.333 & $186 \pm 19$ & $1067 \pm 60$ & $82.5 \pm 2.0$ & $309 \pm 11$ & $1201 \pm 20$ & $74.3 \pm 1.0$ \\
\hline
\end{tabular}

study, these materials exhibited low moisture content (less than $12 \%$ ) and high water absorption capacity ( $440 \%$ for SD and $350 \%$ for $\mathrm{RH}$ ) which are compatible to the purpose of correcting moisture excess of PP. In addition, the high FAS of these components (about $80 \%$ ) indicates that they are able to maintain air spaces between particles in the composting mixture with PP waste and ensure its proper aeration. With respect to GC, this material also exhibits high FAS. However, in this case it decomposes rapidly during composting, and thus it is not a good bulking agent for composting mixtures. On the other hand, its low $\mathrm{C}_{\text {org }} / \mathrm{N}$ ratio turns $\mathrm{GC}$ into a good nitrogen source whenever necessary. In summary, the ingredients selected in this study seem to be adequate to obtain well balanced mixtures, since their properties are complementary.

\subsection{Response regression model analysis}

To evaluate how a specific composition determines the FAS for mixtures containing PP, GC and $\mathrm{RH}$ or SD as bulking agents, experimental responses of FAS were obtained for each trial listed in Table 2. Those responses were fitted to Eqs. (1) to (3) by using Design-Expert ${ }^{\circledR}$. Full cubic, Eq. (4), and special quartic, Eq. (5), models were excluded from the evaluation, because the number of model terms should be less than to the number of unique points in the design (10 in our experimental design).

The polynomial fitting results are presented in Table 3 with respect to common statistical parameters, lack of fit and sequential model sum of squares. In fact, the model summary statistics includes standard deviation, $R_{\mathrm{adj}}^{2}$ (proportional reduction in the variance resulting from fitting the model), $R_{\text {pred }}^{2}$ (amount of variation in new data explained by the model) and PRESS statistic (residual error sum of squares, which describes how well the model fits data).
The lack of fit compares the residual error with the error expected in the response, if the experiment is repeated (pure error). Since it is not desirable that residual error significantly exceeds the pure error, models with a $p$-value greater than 0.1 should be considered. Regarding sequential model sum of squares, this parameter represents the sum of the squared deviations from the mean for each model, and it indicates the overall cumulative improvement in the fit as terms are added.

Among the regression models under consideration, the selection of the best one to predict the experimental response was based on the following criteria: i) Low standard deviation, high $R_{\mathrm{adj}}^{2}$ and $R_{\text {pred }}^{2}$ and low PRESS; ii) Low probability of response improvement as additional terms are added ( $p$-value in the sequential model sum of squares less than 0.05 ); iii) High $p$-value in the lack of fit test.

Therefore, for set A, special cubic model complies with criteria i) and iii); however, the $p$-value associated to the sequential model sum of squares indicates that there is no significant improvement of the model fit due to additional terms. Hence, a quadratic model was selected in this case. For set B, criteria i) and iii) were fulfilled by quadratic and special cubic models. Nevertheless, the probability of response improvement was low for the higher order model, and thus the quadratic model was also selected.

The regression coefficients obtained for the selected models are shown in Table 4. The second order polynomial describing FAS response for mixtures with PP:GC:RH presented a non-linear term $\left(\mathrm{X}_{2} \mathrm{X}_{3}\right)$ that is not significant. Therefore, a reduced model was evaluated, by removing the term with the highest $p$-value until all $p$-values are less than 0.1 (Smith, 2005). This procedure was performed using Design-Expert ${ }^{\circledR}$ and led to the response indicated in Table 4. As a result, parameters $R_{\text {adj }}^{2}$ and $R_{\text {pred }}^{2}$ were slightly improved (from 0.995 to 0.996 and 0.985 to 0.991 , respectively).

Table 3

Model regression statistics for set A (with $\mathrm{RH}$ ) and B (with SD).

\begin{tabular}{|c|c|c|c|c|c|c|}
\hline \multirow[t]{2}{*}{ Regression model } & \multicolumn{4}{|c|}{ Model summary statistics } & \multirow[b]{2}{*}{ Lack of fit $p$-value } & \multirow[b]{2}{*}{$\begin{array}{l}\text { Sequential model sum } \\
\text { of squares } p \text {-value }\end{array}$} \\
\hline & Standard deviation & $R_{\mathrm{adj}}^{2}$ & $R_{\text {pred }}^{2}$ & PRESS & & \\
\hline \multicolumn{7}{|l|}{ Set A } \\
\hline Linear & 8.91 & 0.777 & 0.673 & 1515 & 0.0005 & 0.0001 \\
\hline Quadratic & 1.28 & 0.995 & 0.985 & 69.43 & 0.5469 & $<0.0001$ \\
\hline Special cubic & 1.12 & 0.996 & 0.990 & 45.01 & 0.8036 & 0.1018 \\
\hline \multicolumn{7}{|l|}{ Set B } \\
\hline Linear & 7.88 & 0.850 & 0.794 & 1112 & 0.0003 & $<0.0001$ \\
\hline Quadratic & 1.52 & 0.994 & 0.985 & 78.80 & 0.1226 & $<0.0001$ \\
\hline Special cubic & 1.46 & 0.994 & 0.970 & 161.6 & 0.1256 & 0.2325 \\
\hline
\end{tabular}


Table 4

Regression coefficients of the quadratic model for predicting FAS of set A (with RH) and B (with SD).

\begin{tabular}{|c|c|c|c|c|c|c|c|}
\hline \multicolumn{3}{|l|}{ Set $A$} & \multicolumn{2}{|c|}{ Set A (reduced model) } & \multicolumn{3}{|l|}{ Set B } \\
\hline Coefficient value & Independent variable & $\overline{\text { Term } p \text {-value }}{ }^{\mathrm{a}}$ & Coefficient value & Independent variable & Coefficient value & Independent variable & Term $p$-value ${ }^{\mathrm{a}}$ \\
\hline 34.56 & $\mathrm{X}_{1}$ & & 34.52 & $\mathrm{X}_{1}$ & 24.79 & $\mathrm{X}_{1}$ & \\
\hline 86.40 & $\mathrm{X}_{2}$ & & 86.61 & $\mathrm{X}_{2}$ & 85.74 & $\mathrm{X}_{2}$ & \\
\hline 86.77 & $\mathrm{X}_{3}$ & & 86.97 & $\mathrm{X}_{3}$ & 84.13 & $\mathrm{X}_{3}$ & \\
\hline 50.41 & $\mathrm{X}_{1} \mathrm{X}_{2}$ & $<0.0001$ & 50.81 & $\mathrm{X}_{1} \mathrm{X}_{2}$ & 61.55 & $\mathrm{X}_{1} \mathrm{X}_{2}$ & $<0.0001$ \\
\hline 92.98 & $\mathrm{X}_{1} \mathrm{X}_{3}$ & $<0.0001$ & 93.38 & $\mathrm{X}_{1} \mathrm{X}_{3}$ & 68.66 & $\mathrm{X}_{1} \mathrm{X}_{3}$ & $<0.0001$ \\
\hline 3.24 & $\mathrm{X}_{2} \mathrm{X}_{3}$ & 0.5351 & - & $\mathrm{X}_{2} \mathrm{X}_{3}$ & -38.85 & $\mathrm{X}_{2} \mathrm{X}_{3}$ & 0.0002 \\
\hline
\end{tabular}

${ }^{a}$ If a term is not significant for the model, then $p$-value is $>0.05$ and model reduction should be evaluated.

As usual, obtained models for predicting FAS were based on the assumption that errors are independent and identically distributed with zero mean and homogeneous variance (Smith, 2005). The confirmation of these conditions was performed by visual inspection of the normal probability plot of the studentized residuals (to check for normality of residuals), by comparing their values with the predicted ones (data not shown). Although it was observed some scatter, normal plot of residuals followed a straight line suggesting a normal distribution.

\subsection{Surface and response trace plots analysis}

Trace and surface/contour plots were drawn to evaluate the effects of individual ingredients on FAS response. For sets A and B, surface plots are depicted in Fig. $2 a-b$, which include the projection of the response in a $2 \mathrm{D}$ representation. In these figures, mixture compositions that produced the same response are indicated by a contour line. For both sets A and B, maximum FAS values are located towards pure blends of $\mathrm{GC}$ and $\mathrm{RH} / \mathrm{SD}$. In fact, contour lines in Fig. $2 \mathrm{a}-\mathrm{b}$ indicate a broad range of $\mathrm{GC}$ and $\mathrm{RH} / \mathrm{SD}$ proportions where FAS assume identical values. It should be noted that large amounts of GC may seem to ensure high values for FAS. However, this material decomposes quickly and then tend to compact, reducing pores between compost particles (Rynk et al., 1992). Moreover, the response surface in Fig. 2-b shows that the binary mixture of SD with GC acts antagonistically on FAS parameter, which is reflected in the negative coefficient associated to $\mathrm{X}_{2} \mathrm{X}_{3}$ (Table 4).

The main reason for this result is the great importance of the particle size distribution of the bulking agent to the structural condition of the mixture. In our study, $86 \%$ of SD particles are lower than $2 \mathrm{~mm}$, which is a high value comparing with the one suggested by Haug (1993) (50\% of particles passing a mesh of $2.23 \mathrm{~mm}$ ). By mixing SD with GC, the interstices of GC were probably occupied by sawdust, thus reducing FAS, rather than what is expected of a good bulking agent.

Trace plots, Fig. $2 \mathrm{c}-\mathrm{d}$, enable to compare the effects of all components in the design space and determine the sensitivity of the response to deviations from the formulation near the reference mixture (the centroid of the triangle, design points $n^{\circ} 9$ and 14 from

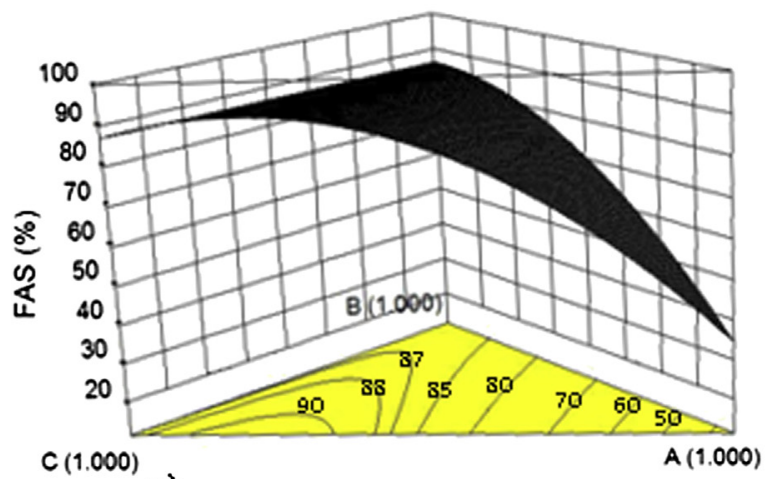

a)

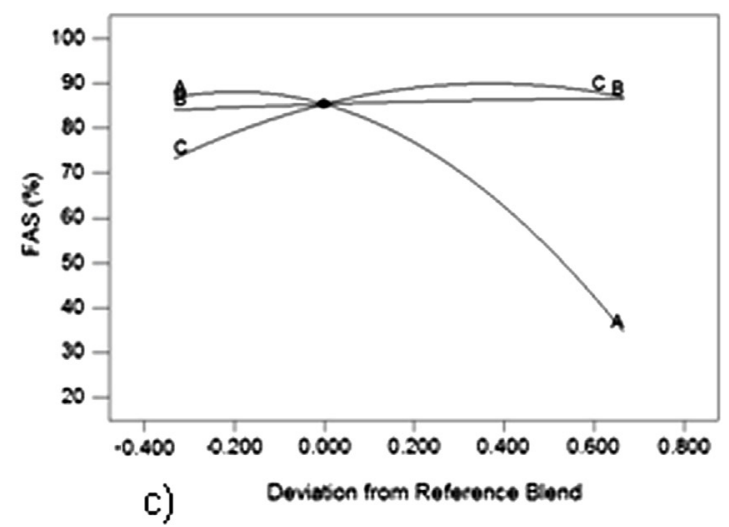

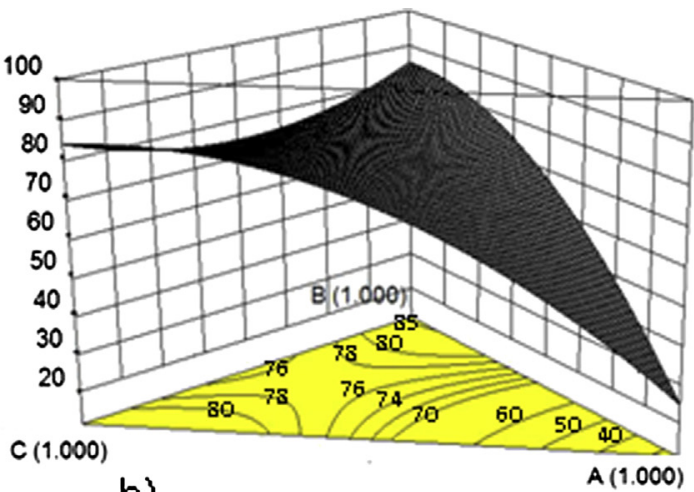

b)

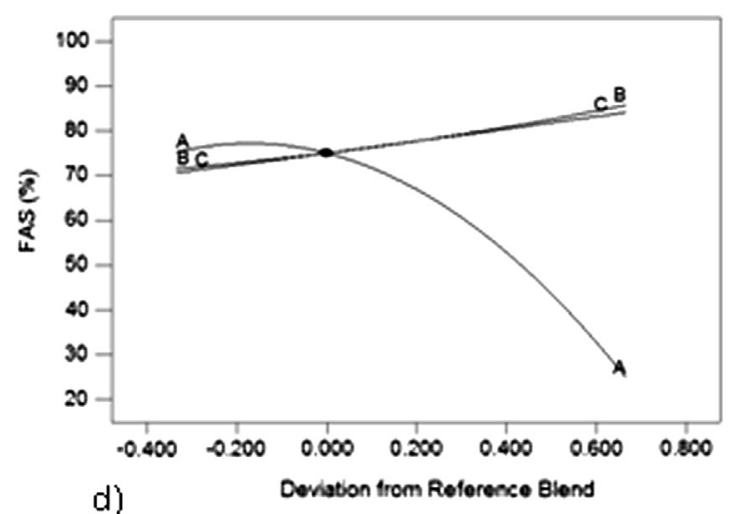

d)

Fig. 2. Contour plots for FAS: a)- set A (A:PP; B: GC; C: RH); b)- set B (A:PP; B: GC; C: SD); response trace plots for FAS: c)- set A; d)- set B. 
Table 1). The lines in Fig. 2 c-d correspond to the FAS response due to variations in the proportions of a selected component, keeping constant the ratio of the others ingredients and the sum of mixture components equal to one. The results reveal that independently of the bulking agent used, PP (ingredient $\mathrm{A}$ ) has a strong effect on the reduction of FAS as mixtures deviate from the centroid. When $\mathrm{RH}$ is used, Fig. 2-c, the response trace to GC is nearly a horizontal line, meaning that it has a negligible effect on FAS. When SD is tested, Fig. 2-d, GC and SD response curves are overlapped, and thus these components have roughly identical linear effect on FAS. This result may be explained by the particle size of the SD used in our study, as previously mentioned.

\subsection{Validation of the response regression model}

Three compositions were selected for each bulking agent, for validating regression models, Eqs (7) and (8), previously obtained for FAS:

$$
\begin{aligned}
\text { FAS }_{\text {Set A }}= & 34.52 X_{1}+86.61 X_{2}+86.97 X_{3}+50.81 X_{1} X_{2} \\
& +93.38 X_{1} X_{3}
\end{aligned}
$$

$$
\begin{aligned}
\text { FAS }_{\text {Set B }}= & 24.79 X_{1}+85.74 X_{2}+84.13 X_{3}+61.55 X_{1} X_{2} \\
& +68.66 X_{1} X_{3}-38.85 X_{2} X_{3}
\end{aligned}
$$

The selection was based on the range of ingredients proportions that are favourable to composting in what concerns $\mathrm{MC}, \mathrm{C}_{\text {org }} / \mathrm{N}$ and FAS. Restrictions imposed to $\mathrm{C}_{\mathrm{org}} / \mathrm{N}$ are in the interval 20-40:1 (Rynk et al., 1992). The upper limit was slightly broadened for MC (55-75\%) due to the high absorption capacity of bulking agents involved (Barrena et al., 2011). Mixture proportions that fulfilled the requirements for $\mathrm{MC}$ and $\mathrm{C}_{\text {org }} / \mathrm{N}$ were calculated according to the principle of mass conservation to a blend of PP, GC and RH or $\mathrm{SD}$, whose characteristics were listed in Table 1. FAS was allowed to vary between 60 and $85 \%$. By combining the constraints of the parameters $\mathrm{MC}, \mathrm{C}_{\mathrm{org}} / \mathrm{N}$ and $\mathrm{FAS}$, an interception area (shaded region in Fig. 3) is defined for selecting the mixtures RH1 to RH3 and SD1 to SD3, for FAS model validation. The numerical results for validating the models described by Eq. (7) and Eq (8) are shown in Table 5. Experimental results for FAS were found to be very close to the predictions of the models, with relative errors ranging from $-2.7-5.8 \%$, but within the prediction intervals. Therefore, the models developed by mixture design approach for predicting FAS, Eqs. (7) and (8), can be used to properly calculate the free air space of ternary mixtures of PP, GC, RH or SD.

In this study FAS was quantified by using the simplest theoretical correlation available, Eq. (6), although air pycnometry is pointed out as the most reliable technique for its determination in composting matrices (Ruggieri et al., 2009). But the unavailability of commercial pycnometers for this type of solid material, conditioned the cross-confirmation of our theoretical correlation based results.

In literature, FAS has been estimated by theoretical or empirical approaches (Alburquerque et al., 2008). Fig. 4 compares FAS predictions of the models developed in our study, Eqs. (7) and (8), with the ones calculated by equations proposed by Richard et al. (2004), Eq. (9), and Agnew et al. (2003), Eq. (10):

$$
\begin{aligned}
\mathrm{FAS}_{\mathrm{R}}= & \left(1-\mathrm{BD} \times\left(\frac{1-\mathrm{DM}}{D_{w}}+\frac{\mathrm{DM} \times \mathrm{OM}}{\mathrm{PD}_{\mathrm{OM}}}+\frac{\mathrm{DM} \times(1-\mathrm{OM})}{\mathrm{PD}_{\mathrm{ash}}}\right)\right) \\
& \times 100 \%
\end{aligned}
$$

$\mathrm{FAS}_{\mathrm{Ag}}=100-0.0889 \times \mathrm{BD}$

where BD is the wet bulk density $\left(\mathrm{kg} \mathrm{m}^{-3}\right)$, DM the fraction of dry matter, OM the fraction of organic matter in dry basis, $D_{w}$ the density of water $\left(\mathrm{kg} \mathrm{m}^{-3}\right), \mathrm{PD}_{\mathrm{OM}}$ the particle density of organic matter $\left(2500 \mathrm{~kg} \mathrm{~m}^{-3}\right)$ and $\mathrm{PD}_{\mathrm{ash}}$ the particle density of ash $\left(1600 \mathrm{~kg} \mathrm{~m}^{-3}\right)$.

In general, for mixtures RH1 to RH3, FAS calculated by Eqs. (9) and (10) are slightly higher than the predicted by models of our study, Eqs. (7) and (8). However, in the case of SD1 to SD3 (sawdust as bulking agent), correlations values fitted inside the prediction intervals. These differences might be related to the applicability conditions of theoretical and empirical approaches for FAS quantification. According to Ruggieri et al. (2009), properties such as BD and $\mathrm{MC}$ have a strong influence on FAS estimated by these correlations, and boundaries were established to its application. Namely,
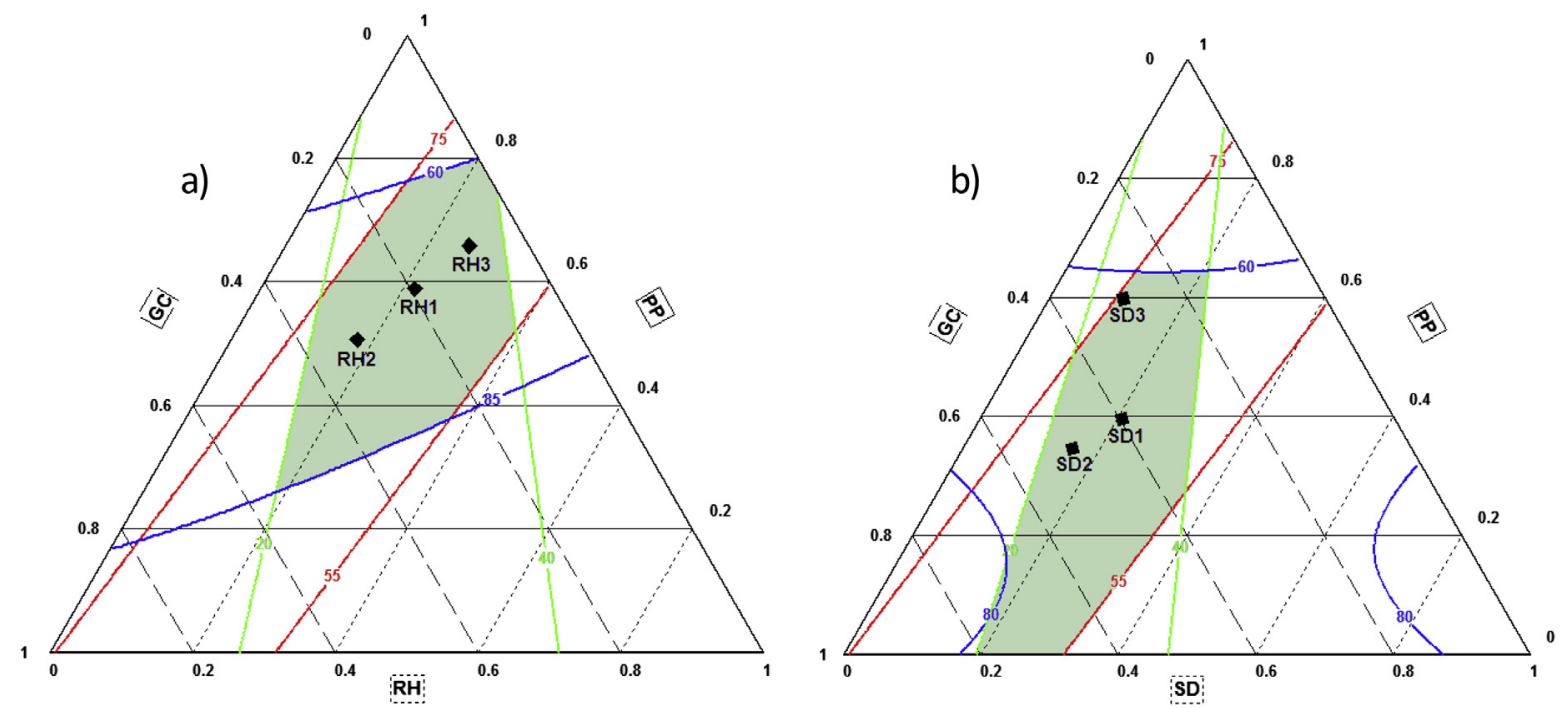

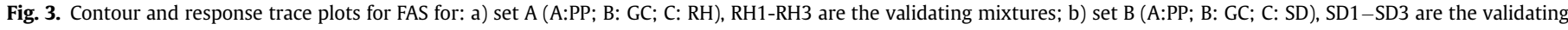
mixtures. 
Table 5

Experimental conditions tested and validation results.

\begin{tabular}{|c|c|c|c|c|c|c|c|c|c|}
\hline \multirow[t]{2}{*}{ Mixt. ref. } & \multirow[t]{2}{*}{$\mathrm{X}_{1}(\mathrm{PP})$} & \multirow[t]{2}{*}{$\mathrm{X}_{2}(\mathrm{GC})$} & \multirow[t]{2}{*}{$\mathrm{X}_{3}(\mathrm{RH}$ or $\mathrm{SD})$} & \multirow[t]{2}{*}{ MC (\%) } & \multirow[t]{2}{*}{ VS (\%) } & \multirow[t]{2}{*}{$\mathrm{BD}\left(\mathrm{kg} \mathrm{m}^{-3}\right)$} & \multicolumn{3}{|l|}{ FAS (\%) } \\
\hline & & & & & & & Exp. result & Model prediction & Pred. interval \\
\hline RH1 & 0.587 & 0.192 & 0.219 & 70.5 & 86.7 & 240 & 75.8 & 73.9 & \pm 4.2 \\
\hline $\mathrm{RH} 2$ & 0.506 & 0.324 & 0.170 & 69.6 & 85.9 & 229 & 76.4 & 76.7 & \pm 4.0 \\
\hline RH3 & 0.660 & 0.081 & 0.259 & 64.3 & 86.2 & 245 & 73.9 & 71.0 & \pm 4.5 \\
\hline SD1 & 0.400 & 0.400 & 0.200 & 67.5 & 90.5 & 325 & 71.3 & 73.3 & \pm 5.3 \\
\hline SD2 & 0.343 & 0.516 & 0.141 & 71.4 & 88.5 & 268 & 78.3 & 76.0 & \pm 5.3 \\
\hline SD3 & 0.600 & 0.300 & 0.100 & 70.8 & 90.0 & 440 & 66.9 & 63.0 & \pm 6.5 \\
\hline
\end{tabular}

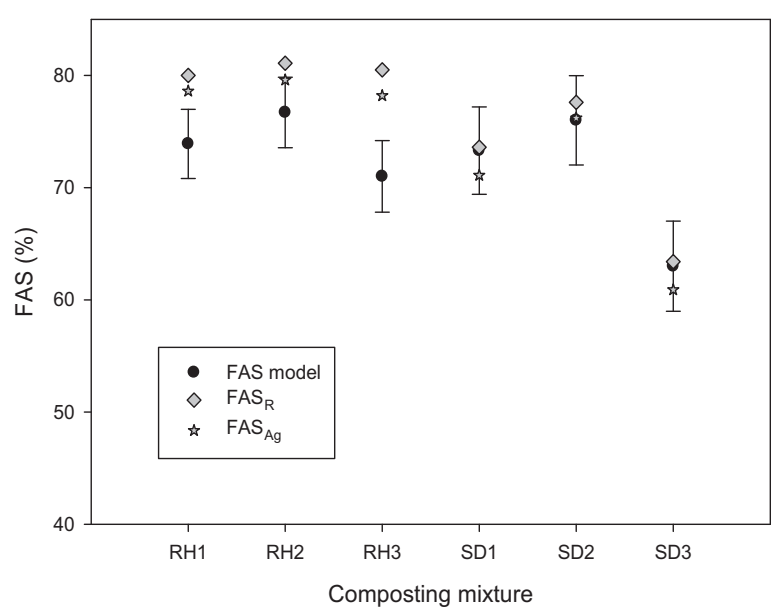

Fig. 4. Comparison between FAS predictions error bars indicate prediction intervals with a significance of $95 \%$.

$\mathrm{FAS}_{\mathrm{R}}$, Eq. (9), is limited for materials where $\mathrm{BD}$ is superior to $400 \mathrm{~kg} \mathrm{~m}^{-3}$; below this level $\mathrm{FAS}_{\mathrm{R}}$ may lead to misleading values. Also $F_{A S}$, Eq. (10), seems restricted only to high-moisture and/or low-density materials where $\mathrm{FAS}_{\mathrm{R}}$ may provide misleading values. In our study, mixtures with $\mathrm{RH}$ have low bulk densities $\left(<245 \mathrm{~kg} \mathrm{~m}^{-3}\right)$ and $\mathrm{FAS}_{\mathrm{R}}$ were the highest ones, over estimating $\mathrm{FAS}_{\text {model }}$ (relative error ranged from -5.7 to $-13.3 \%$ ). FAS indicated by FAS $_{\mathrm{Ag}}$ were also overestimated but within the relative errors $(-3.8$ to $-10.1 \%)$. For mixtures with $\mathrm{SD}, \mathrm{FAS}_{\mathrm{R}}$ were more consistent with $\mathrm{FAS}_{\text {model }}$ predictions, especially for mixtures with higher bulk density (SD1 and SD3).

\section{Conclusions}

This study aimed to predict free air space of mixtures for further used in composting, based on mixture design approach. The organic materials tested were potato peel (PP), grass clippings (GC) and rice husks ( $\mathrm{RH})$ or sawdust (SD). The results proved that the mixture design methodology led to reliable mathematical models for predicting FAS of mixtures containing primarily PP. In particular, for mixtures with PP, GC and SD the FAS model pointed out the antagonistic effect of the binary mixture of GC and SD to the overall property. Contour plots revealed the occurrence of a wide range of GC and SD (bulking agent) proportions where FAS assume identical values; nonetheless, large proportions of GC should be avoided.

As expected, response trace plots clearly indicated that independently of the bulking agent used, the addition of potato peel has a strong effect on reducing the mixture air voids volume.

The models obtained for predicting FAS were compared with theoretical and empirical correlations proposed in literature which consider mixture properties like DM, OM and BD. For formulations with SD, correlations are consistent with our model prediction.
When RH was used as bulking agent both literature correlations overestimated the FAS but even so the deviations were low.

In summary, mixture design approach led to good results to estimate FAS of initial mixtures with industrial potato peel waste, avoiding, this way, trial and error methods often used to establish the ingredients proportions. By overlapping contour plots that describe the influence of the mixture composition in FAS, it was possible to find a range that complies with requirements in what concerns moisture content, $\mathrm{C} / \mathrm{N}$ ratio and FAS.

Future studies should address how model predictions are affected by two aspects: 1) variability of wet basis properties since they affect the surface areas of the feedstock particles and pore space formation and 2) biodegradability of the mixture, because when the materials decompose quickly, pores between particles are reduced and composting evolution may be hindered.

\section{Acknowledgements}

The authors kindly thank S\&A, Ernesto Morgado and AAC for providing the composting materials. Micaela A.R. Soares gratefully acknowledges the Fundação para a Ciência e Tecnologia, Portugal, for the financial support of Program PROTEC2 (SFRH/PROTEC/ $67369 / 2009$ ). The CERNAS is supported by National Funds through FCT - Foundation for Science and Technology under the project "PEst-OE/AGR/UI0681/2011».

\section{References}

Abdullah, N., Chin, N.L., 2010. Simplex-centroid mixture formulation for optimised composting of kitchen waste. Bioresource Technology 101 (21), 8205-8210.

Adhikari, B.K., Barrington, S., Martinez, J., King, S., 2008. Characterization of food wastes and bulking agents for composting. Waste Management 28 (5), 795804.

Adhikari, B.K., Barrington, S., Martinez, J., King, S., 2009. Effectiveness of three bulking agents for food waste composting. Waste Management 29 (1), 197-203.

Agnew, J., Leonard, J., Feddes, J., Feng, Y., 2003. A modified air pycnometer for compost air volume and density determination. Canadian Biosystems Engineering 45, 627-635.

Ahn, H.K., Richard, T.L., Glanville, T.D., 2008. Laboratory determination of compost physical parameters for modeling of airflow characteristics. Waste Management 28 (3), 660-670.

Akalin, O., Akay, K.U., Sennaroglu, B., Tez, M., 2010. Optimization of chemical admixture for concrete on mortar performance tests using mixture experiments. Chemometrics and Intelligent Laboratory Systems 104 (2), 233-242.

Al-Weshahy, A., El-Nokety, M., Bakhete, M., Rao, V., 2013. Effect of storage on antioxidant activity of freeze-dried potato peels. Food Research International 50 (2), 507-512.

Alburquerque, J.A., Mccartney, D., Yu, S., Brown, L., Leonard, J.J., 2008. Air space in composting research: a literature review. Compost Science \& Utilization 16 (3), 159-170.

Arapoglou, D., Varzakas, T., Vlyssides, A., Israilides, C., 2010. Ethanol production from potato peel waste (PPW). Waste Management 30 (10), 1898-1902.

Barrena, R., Turet, J., Busquets, A., Farrés, M., Font, X., Sánchez, A., 2011. Respirometric screening of several types of manure and mixtures intended for composting. Bioresource Technology 102 (2), 1367-1377.

Chang, J.I., Hsu, T.-E., 2008. Effects of compositions on food waste composting. Bioresource Technology 99 (17), 8068-8074.

Chang, C.-T., Lee, C.-H., Chiou, C.-S., Jeng, F.-T., 1999. Recovery assessment of lumber mill wastes: composting product field test. Resources. Conservation and Recycling 25 (2), 133-150. 
Djomo, S., Humbert, S., Blumberga, D., 2008. Life cycle assessment of hydrogen produced from potato steam peels. International Journal of Hydrogen Energy 33 (12), 3067-3072.

Eftoda, G., McCartney, D., 2004. Determining the critical bulking agent requirement for municipal biosolids composting. Compost Science \& Utilization 12 (3), 208 218.

Eriksson, L., 1998. Mixture design-design generation, PLS analysis, and model usage. Chemometrics and Intelligent Laboratory Systems 43 (1-2) $1-24$

Gao, M., Liang, F., Yu, A., Li, B., Yang, L., 2010. Evaluation of stability and maturity during forced-aeration composting of chicken manure and sawdust at different $\mathrm{C} / \mathrm{N}$ ratios. Chemosphere 78 (5), 614-619.

Hamoda, M., Abuqdais, H., Newham, J., 1998. Evaluation of municipal solid waste composting kinetics. Resources, Conservation and Recycling 23 (4), 209-223.

Haug, R.T., 1993. The Practical Handbook of Compost Engineering. CRC-Press, Florida.

Huang, G.F., Wu, Q.T., Wong, J.W.C., Nagar, B.B., 2006. Transformation of organic matter during co-composting of pig manure with sawdust. Bioresource Technology 97 (15), 1834-1842.

Jolanun, B., Towprayoon, S., Chart, C., 2008. Aeration improvement in fed batch composting of vegetable and fruit wastes. Environmental Progress 27 (2), 250-256.

Kaparaju, P., Rintala, J., 2005. Anaerobic co-digestion of potato tuber and its industrial by-products with pig manure. Resources, Conservation and Recycling 43 (2), 175-188

Kryvoruchko, V., Machmüller, A., Bodiroza, V., Amon, B., Amon, T., 2009. Anaerobic digestion of by-products of sugar beet and starch potato processing. Biomass and Bioenergy 33 (4), 620-627.

Liang, C., Das, K.C., McClendon, R.W., 2003. The influence of temperature and moisture contents regimes on the aerobic microbial activity of a biosolids composting blend. Bioresource Technology 86 (2), 131-137.

Mars, A.E., Veuskens, T., Budde, M.A.W., van Doeveren, P.F.N.M., Lips, S.J., Bakker, R.R., de Vrije, T., Claassen, P., 2010. Biohydrogen production from untreated and hydrolyzed potato steam peels by the extreme thermophiles Caldicellulosiruptor saccharolyticus and Thermotoga neapolitana. International Journal of Hydrogen Energy 35 (15), 7730-7737.
Nakasaki, K., Shoda, M., Kubota, H., 1986. Effects of a bulking agent on the reaction rate of thermophilic sewage sludge composting. Journal of Fermentation Technology 64 (6), 539-544.

Nakasaki, K., Shoda, M., Kubota, H., 1989. Nitrogen transformation during thermophilic composting. Journal of Fermentation and Bioengineering 67 (1), 57-61.

Oppenheimer, J.R., Martin, A., Walker, L.P., 1997. Measurements of air-filled porosity in unsaturated organic matrices using a pycnometer. Bioresource Technology 59, 241-247.

Parawira, W., Murto, M., Zvauya, R., Mattiasson, B., 2004. Anaerobic batch digestion of solid potato waste alone and in combination with sugar beet leaves. Renewable Energy 29 (11), 1811-1823.

Richard, T.L., Veeken, A., de Wilde, V., Hamelers, H., 2004. Air-filled porosity and permeability relationships during solid-state fermentation. Biotechnology Progress 20, 1372-1381.

Ruggieri, L., Gea, T., Artola, A., Sánchez, A., 2009. Air filled porosity measurements by air pycnometry in the composting process: a review and a correlation analysis. Bioresource Technology 100 (10), 2655-2666.

Rynk, R., van de Kamp, M., Willson, G.B., Singley, M.E., Richard, T.L., Kolega, J.J., et al. 1992. In: Rynk, R. (Ed.), On-farm composting handbook. Northeast Regional Agricultural Engineering Service, Ithaca.

Schaub, S.M., Leonard, J.J., 1996. Composting: an alternative waste management option for food processing industries. Trends in Food Science \& Technology 7, 263-268.

Schieber, A., Stintzing, F.C., Carle, R., 2001. By-products of plant food processing as a source of functional compounds - recent developments. Trends in Food Science \& Technology 12 (11), 401-413.

Smith, W.F., 2005. Experimental Design for Formulation. Society for Industrial and Applied Mathematics, Pittsford, New York.

Soares, M., Andrade, S., Martins, R., Quina, M., Quinta-Ferreira, R., 2012. Organic biowastes blend selection for composting industrial eggshell by-product: experimental and statistical mixture design. Water Science \& Technology 65 (11), 1939-1945.

US Department of Agriculture and US Composting Council, 2001. Test Methods for the Examination of Composting and Compost. Edaphos International, Houston.

Wijngaard, H.H., Ballay, M., Brunton, N., 2012. The optimisation of extraction of antioxidants from potato peel by pressurised liquids. Food Chemistry 133 (4), $1123-1130$ 